\title{
Molecular characterization of the duck enteritis virus US10 protein
}

\author{
Daixi Zhang ${ }^{1,2,3 \dagger}$, Maoyin Lai ${ }^{1,2,3 \dagger}$, Anchun Cheng ${ }^{1,2,3^{*}}$, Mingshu Wang ${ }^{1,2,3^{*}}$, Ying Wu ${ }^{1,2,3}$, Qiao Yang ${ }^{1,2,3}$, \\ Mafeng Liu ${ }^{1,2,3}$, Dekang Zhu ${ }^{1,2,3}$, Renyong Jia ${ }^{1,2,3}$, Shun Chen ${ }^{1,2,3}$, Kunfeng Sun ${ }^{1,2,3}$, Xinxin Zhao ${ }^{1,2,3}$ \\ and Xiaoyue Chen $^{2}$
}

\begin{abstract}
Background: There is little information regarding the duck enteritis virus (DEV) US10 gene and its molecular characterization.

Methods: Duck enteritis virus US10 was amplified and cloned into the recombinant vector pET32a(+). The recombinant US10 protein was expressed in Escherichia coli BL21 cells and used to immunize rabbits for the preparation of polyclonal antibodies. The harvested rabbit antiserum against DEV US10 was detected and analyzed by agar immunodiffusion. Using this antibody, western blotting and indirect immunofluorescence analysis were used to analyze the expression level and subcellular localization of US10 in infected cells at different time points. Quantitative reverse-transcription PCR (qRT-PCR) and pharmacological inhibition tests were used to ascertain the kinetic class of the US10 gene. A mass spectrometrybased strategy was used to identify US10 in purified DEV virions and quantify its abundance.

Results: The recombinant pET32a(+)/US10 protein was expressed as inclusion bodies, purified by gradient urea washing, and used to prepare specific antibodies. The results of qRT-PCR, western blotting, and pharmacological inhibition tests revealed that US10 is mainly transcribed in the late stage of viral replication. However, the presence of the DNA polymerase inhibitor ganciclovir and the protein synthesis inhibitor cycloheximide blocked transcription. Therefore, US10 is a Y2 (true late) gene. Indirect immunofluorescence analysis showed that US10 proteins were initially diffusely distributed throughout the cytoplasm, but with the passage of time, they gradually relocated to a perinuclear region. The US10 protein was detected in purified DEV virions by mass spectrometry, but was not detected by western blotting, indicating that DEV US10 is a minor virion protein.
\end{abstract}

Conclusions: The DEV US10 gene is a Y2 gene and the US10 protein is localized in the perinuclear region. DEV US10 is a virion component.

Keywords: Duck enteritis virus, US10, Kinetic class, True late gene, y2 Gene, Subcellular localization, Virion protein

\section{Background}

Duck viral enteritis (DVE) is an acute, hemorrhagic, highly contagious disease of waterfowl caused by duck enteritis virus (DEV) [1,2]. Since it was first reported in the Netherlands, this fatal pathogen has resulted in significant economic losses in domestic and wild waterfowl due to high mortality and decreased egg production [3]. In 2015, DEV was classified as an Alphaherpesvirinae (genus

\footnotetext{
* Correspondence: chenganchun@vip.163.com; mshwang@163.com ${ }^{\dagger}$ Equal contributors

${ }^{1}$ Institute of Preventive Veterinary Medicine, Sichuan Agricultural University, Wenjiang 611130, People's Republic of China

Full list of author information is available at the end of the article
}

Mardivirus) according to the 10th report of the International Committee on Taxonomy of Viruses (ICTV) [4].

The complete sequences of different DEV strains have been published in GenBank, including three field (virulent) strains (CHv, 2085, and CSC) and five attenuated strains (C-KCE, VAC, Clone-03, CV, and K) [5-9]. The smallest DEV US10 protein has been reported to be 168 aa (C$\mathrm{KCE}$ ), while the largest one has been found in the $\mathrm{CHv}$ strain (322 aa). The US10 sequence of VAC has 100\% identity to those of Clone-03 and $\mathrm{K}$, while the 2085 sequence is $100 \%$ identical to those of $\mathrm{CHv}$ and CSC. An absence of a thymidine at position 787 of $\mathrm{CHv}$ and 2085 strains result in modification of the downstream 35 amino 
acids and an additional stretch of 11 amino acids. This mutation is identical in virulent and absent in attenuated strains, suggesting that DEV US10 may be involved in the process of attenuation $[6,7]$.

DEV US10 homologs were found in MDV, HVT, HSV-1, HSV-2, CeHV-1, EHV-1, EHV-4, VZV, and ILTV. The percentage homology ranges from 18.3 to $31.0 \%[8,9]$. The US10 homologs of EHV-1, HSV-1, and VZV are known to possess a sequence of 13 amino acids (C-X3-C-X3-H-X3$\mathrm{C})$, which is a perfect match to the consensus $\mathrm{CCHC}$-type zinc finger domain [8-11]. The US10 gene is predicted to encode a tegument phosphoprotein in other alphaherpesviruses that can interact with host proteins and other viral proteins to play a role in virulence and pathogenicity $[10,12,13]$. However, the molecular characteristics and related functions of the DEV US10 gene have not yet been reported. Therefore, we expressed the recombinant US10 protein in a prokaryotic expression system to generate antiserum that recognizes US10 to better investigate its expression levels and subcellular localization in DEV-infected cells. The transcription phases and gene type of US10 were also determined through RT-PCR and pharmacological inhibition tests. We also detected US10 protein and its relative abundance in extracellular DEV virions by western blotting and mass spectrometry. This work provides a foundation for further studies on the function of DEV US10.

\section{Methods}

Viruses, strains, vectors, and other significant materials

The CHv strain of DEV (GenBank accession number: JQ647509), E. coli BL21 cells, E. coli DH5 $\alpha$ cells, the prokaryotic expression vector $\mathrm{pET}-32 \mathrm{a}(+), \mathrm{pMD} 18-\mathrm{T} / \beta-$ actin, the rabbit anti-DEV serum, and rabbit anti-gC serum were preserved and provided by the Avian Diseases Research Center, College of Veterinary Medicine, Sichuan Agricultural University. The pET32a(+)/US10 vector was constructed by Takara Biotechnology Co. (Dalian, China). Monolayer cultures of duck embryo fibroblasts (DEFs) were cultured in Minimal Essential Medium (MEM;
Gibco) containing 10\% fetal bovine serum (FBS; Gibco) and $100 \mu \mathrm{g} / \mathrm{mL}$ streptomycin. After DEV inoculation, the DEFs were incubated in MEM containing 3\% FBS.

\section{PCR amplification and plasmid construction}

All primers (Table 1) were designed by Oligo7.0, and P1/ P2 were used to amplify DEV US10 (GenBank accession number: EU195084). The amplified product was sent to Takara to generate the prokaryotic expression plasmid pET32a $(+) /$ US10 (data not shown). P3/P4 and P5/P6 were used to amplify DEV US10 and the duck $\beta$-actin gene by qRT-PCR, respectively. P7/P8 were used to amplify the DEV UL55 (GenBank: EU071034) gene, as a $\gamma 2$ gene control $[14,15]$.

\section{Prokaryotic expression}

The recombinant plasmid pET-32a(+)/US10 was transformed into E. coli BL21 cells, which were then induced using IPTG at a working concentration of $0.6 \mathrm{mM}$ for $6 \mathrm{~h}$ at $37^{\circ} \mathrm{C}$. After centrifugation, the cells were resuspended in $20 \mathrm{mM}$ Tris- $\mathrm{HCl}$. The expression of the recombinant protein was determined using SDS-PAGE after the disruption of cells by cold sonication. The reactivity of recombinant proteins was determined by western blot analysis using rabbit anti-DEV serum as the primary antibody and HRPlabeled goat anti-rabbit IgG as the secondary antibody.

Preparation and identification of the polyclonal antibody The recombinant US10 protein was mainly expressed as inclusion bodies, purified through urea washing, dialysis, and renaturation, as described by $\mathrm{Wu}$ et al. [16]. Six healthy male rabbits were selected and immunized once a week to prepare the polyclonal antibody [17]. After four immunizations, blood was collected from the ear vein and the antibody titer was measured by the agar dilution method. After reaching the target titer, blood was taken from the heart to obtain rabbit anti-US10 polyclonal antibodies.

The reactivity of the antibody was determined using western blot analysis [18]. On the one hand, the lysates

Table 1 Sequence and characteristics of primer pairs

\begin{tabular}{|c|c|c|c|}
\hline Primer & Primer sequence $\left(5^{\prime}-3^{\prime}\right)$ & Gene & Product size (bp) \\
\hline P1 & GAATTCATGAAGAGGCGCTGTCTCAAT & DEV US10 & 988 \\
\hline P2 & AAGCTTTAGAGTATCAGTCAGAGTCATCGTAG & & \\
\hline P3 & CATCCAGTTGCTCCCGT & DEV US10 (for qRT-PCR) & 131 \\
\hline P4 & GCGTGACCTAGACAACACC & & \\
\hline P5 & CGGGCATCGCTGACA & Duck $\beta$-actin gene & 177 \\
\hline P6 & GGATTCATCATACTCCTGCTTGCT & & \\
\hline P7 & AAGATGCTATGCTGCTAATA & DEV UL55 & 740 \\
\hline P8 & СTGTTCGATCTTTACTATTA & & \\
\hline
\end{tabular}


of bacteria transformed with pET-32a $(+)$ vs. pET-32a $(+) /$ US10 were blotted to test the cross-reactivity of antiUS10 serum. On the other hand, the DEV-infected or mock-infected DEFs were collected and probed with anti-US10 serum to detect the DEV US10 protein. HRPlabeled goat anti-rabbit IgG was used as the secondary antibody in two western blotting analyses.

\section{Real-time PCR (RT-PCR)}

Total RNA was extracted from DEV-infected DEFs at different time points post-infection $(0.5,1,2,4,6,8,12$, 16, 24, 36, and $72 \mathrm{~h}$ ) using Trizol, followed by DNase treatment during RNA extraction. The quality of the RNA samples was assessed and the samples were reverse-transcribed to CDNA, as described by $\mathrm{Li}$ et al. [19]. Subsequently, real-time PCR was performed in a $20-\mu \mathrm{L}$ reaction volume containing $10 \mu \mathrm{L}$ of SYBR Green Super Mix, $1 \mu \mathrm{L}$ of each primer, $1 \mu \mathrm{L}$ of cDNA, and $7 \mu \mathrm{L}$ of ultrapure water. The thermal cycling procedure was carried out as follows: initial denaturation for $1 \mathrm{~min}$ at $95{ }^{\circ} \mathrm{C}$ followed by 45 cycles of denaturation at $95{ }^{\circ} \mathrm{C}$ for $5 \mathrm{~s}$, annealing at $59^{\circ} \mathrm{C}$ for $20 \mathrm{~s}$, and extension at $72{ }^{\circ} \mathrm{C}$ for $25 \mathrm{~s}$. Triplicate experiments were performed to analyze the expression of the US10 and $\beta$-actin genes, and the relative transcription level of the DEV US10 gene was calculated using the $2^{-\Delta \mathrm{Ct}}$ method simplified from the $2^{-\Delta \Delta C t}$ method. To evaluate the efficiency of each assay, standard curves were constructed using tenfold serial dilutions of pMD18-T/US10 and pMD18-T/ $\beta$-actin.

\section{Pharmacological inhibition tests}

Pharmacological inhibition tests were performed to confirm the kinetics of DEV US10 [10, 14]. Three bottles of DEFs were prepared and inoculated with DEV, one bottle without any drugs, and the other bottles containing $300 \mu \mathrm{g} / \mathrm{mL}$ ganciclovir (GCV, DNA polymerase synthesis inhibitor) or $100 \mu \mathrm{g} / \mathrm{mL}$ cyclohexamide (CHX, protein synthesis inhibitor). The infected cells were harvested $24 \mathrm{~h}$ after infection and washed twice with PBS. Extraction of total RNA and preparation of cDNA were performed similar to that described above for RT-PCR. The gene type of US10 was identified by PCR (UL55 and $\beta$-actin were used as a $\gamma^{2}$ gene control and a housekeeping gene control, respectively).

\section{Indirect immunofluorescence assay (IFA)}

IFA was conducted using a standard procedure [18]. Briefly, DEV-infected cells were harvested at 12, 24, 36, and $48 \mathrm{~h}$ post-infection, plated onto coverslips, and fixed with $4 \%$ paraformaldehyde for $30 \mathrm{~min}$. The fixed cells were permeabilized with $0.5 \%$ Triton X-100 and incubated for $30 \mathrm{~min}$ in $5 \% \mathrm{BSA}$ at $37{ }^{\circ} \mathrm{C}$. The anti-US10 antibody and FITC-conjugated goat anti-rabbit IgG were used as primary and secondary antibodies, respectively, to sequentially probe the blots for $1 \mathrm{~h}$. Subsequently, the cells were treated with DAPI for $10 \mathrm{~min}$ to stain the nucleus. Images were captured using a fluorescence microscope after the coverslips had been sealed with glycerin buffer on glass slides.

\section{Virion purification}

DEF cells were mock-treated or infected with DEV CHv strain at an MOI of 5 . At $2 \mathrm{hpi}$, the cells were washed twice with PBS and the medium was replaced by serumfree MEM. At $72 \mathrm{hpi}$, the medium was collected and clarified by low-speed centrifugation $\left(2000 \times g, 20 \mathrm{~min}, 4{ }^{\circ} \mathrm{C}\right)$ to remove the cell debris. Extracellular DEV virions were harvested by ultracentrifugation $\left(40,000 \times g, 2 \mathrm{~h}, 4{ }^{\circ} \mathrm{C}\right)$ through a $30 \%(\mathrm{wt} / \mathrm{vol})$ sucrose cushion. Virions were then banded by isopycnic gradient ultracentrifugation in a continuous 30 to $60 \%(\mathrm{wt} / \mathrm{vol})$ potassium tartrate gradient in TBS $\left(40,000 \times g, 2 \mathrm{~h}, 4{ }^{\circ} \mathrm{C}\right)$. The band containing virions was collected, diluted tenfold in TBS, and pelleted by ultracentrifugation $(20,000 \times g, 30 \mathrm{~min}$,
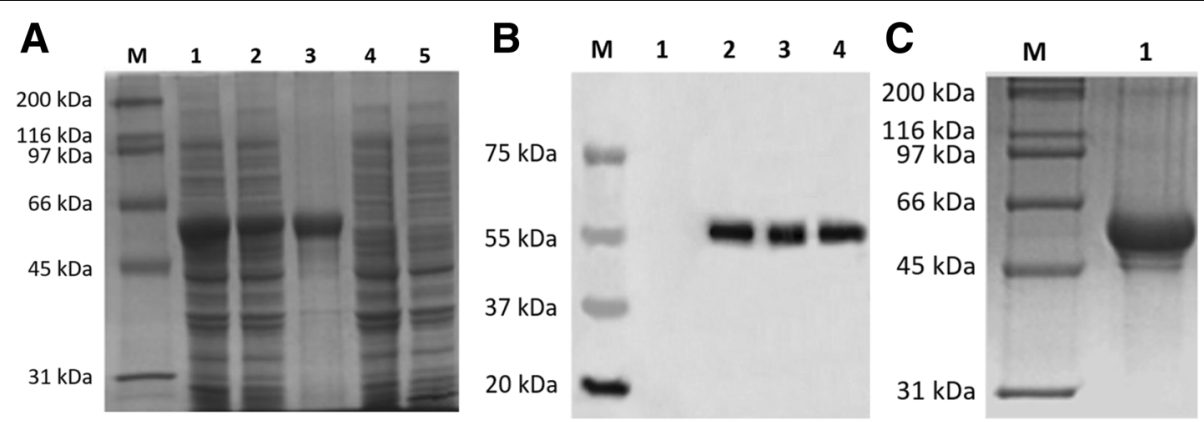

Fig. 1 Expression, identification, and purification of the recombinant US10 protein. a Expression of the recombinant protein. Total protein stain. Lane M: markers; lanes 1-3: the whole bacterial lysate, supernatant, and inclusion bodies of pET32a(+)/US10; lanes 4 and 5: the induced and uninduced pET32a(+). b Identification of the recombinant protein by western blotting with anti-DEV serum; lane M: markers; lane 1: pET32a(+); lanes 2-4: the whole bacterial lysate, supernatant, and inclusion bodies of pET32a(+)/US10. c Purification of the recombinant US10 protein. Detection with anti-DEV serum. Lane M: markers; lane 1: purified recombinant pET32a(+)/US10 protein 

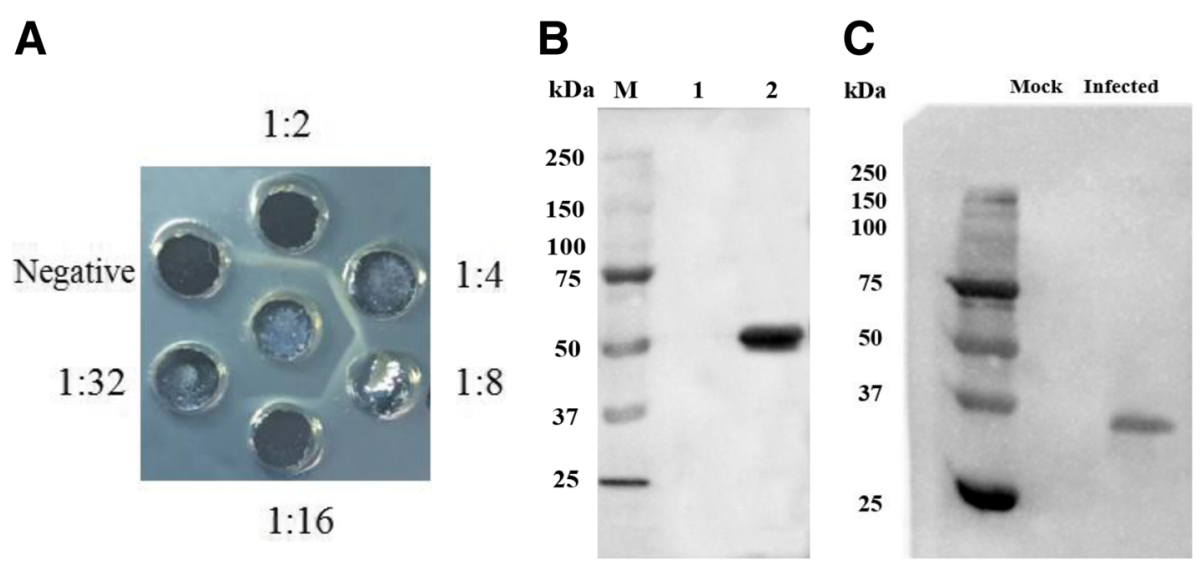

Fig. 2 Preparation and verification of the polyclonal antibody raised against DEV US10. a Agar diffusion reaction test. Middle well: purified recombinant pET32a(+)/US10 protein. $\mathbf{b}$ Cross-reactivity test; lane M: markers; lane 1: the cell lysates of pET32a(+); lane 2: the cell lysates of pET32a(+)/US10. c The DEV US10 was recognized by purified polyclonal antibody. Lane 1: mock-treated DEFs; lane 2: DEV-infected DEFs

$\left.4{ }^{\circ} \mathrm{C}\right)$. The pellet was finally resuspended in TBS and stored at $-80{ }^{\circ} \mathrm{C}$.

\section{Western blotting}

Purified virion samples were boiled for 10 min in $5 \times$ SDSloading buffer and separated on $12 \%$ gels by SDS-PAGE. Proteins were transferred from the gels to polyvinylidene difluoride (PVDF) membranes, which were then blocked for $2 \mathrm{~h}$ in 5\% BSA. All primary antibodies were diluted in blocking buffer and added to blots for $2 \mathrm{~h}$. Blots were then washed three times in TBST and probed with HRPconjugated goat anti-rabbit IgG secondary antibody.

\section{Mass spectrometry}

Purified virion samples were separated by SDS-PAGE. The whole gel was stained with Coomassie brilliant blue and then sent to Sangon Biotech Company (Shanghai, China) for liquid chromatography-tandem mass spectrometry (LC-MS/ MS) analysis. Details of in-gel trypsin digestion, LC-MS/MS, and database searches were as described previously by Loret et al. [20], Leroy et al. [21], and Johannsen et al. [22].

\section{Results}

Expression, identification, and purification of recombinant DEV US10

The expression of recombinant protein (approximately $56.0 \mathrm{kDa}$, including DEV US10, a His-tag, and thioredoxin) was observed by SDS-PAGE after the plasmids pET$32 \mathrm{a}(+) / \mathrm{US} 10$ and pET-32a $(+)$ had been transformed into $E$. coli BL21 cells and induced by IPTG (Fig. 1a). Lanes 1-3 yielded target bands of $56 \mathrm{kDa}$, while no desired bands were observed in lanes 4 and 5 , suggesting that the recombinant proteins were mainly expressed as inclusion bodies. Western blotting was then carried out to verify the reactivity of the recombinant protein. Rabbit anti-DEV serum and HRP-labeled goat anti-rabbit IgG were used as the primary and secondary antibodies, respectively. The results showed that the recombinant protein had good reactivity with the anti-DEV serum (Fig. 1b). Finally, the inclusion bodies were purified through urea washing (Fig. 1c) and used to immunize rabbits.

\section{Purification and verification of US10 antibodies}

The harvested antiserum was titered by the agar diffusion assay. The results showed a maximum titer of 1:16

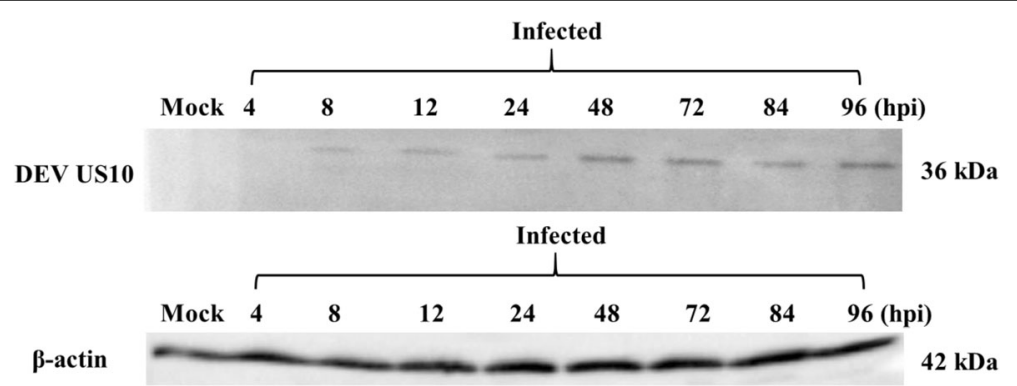

Fig. 3 Expression of US10 protein and $\beta$-actin in DEV-infected cells. Proteins isolated from mock or DEV-infected cells at different times were subjected to western blot analysis with US10 or $\beta$-actin antiserum 


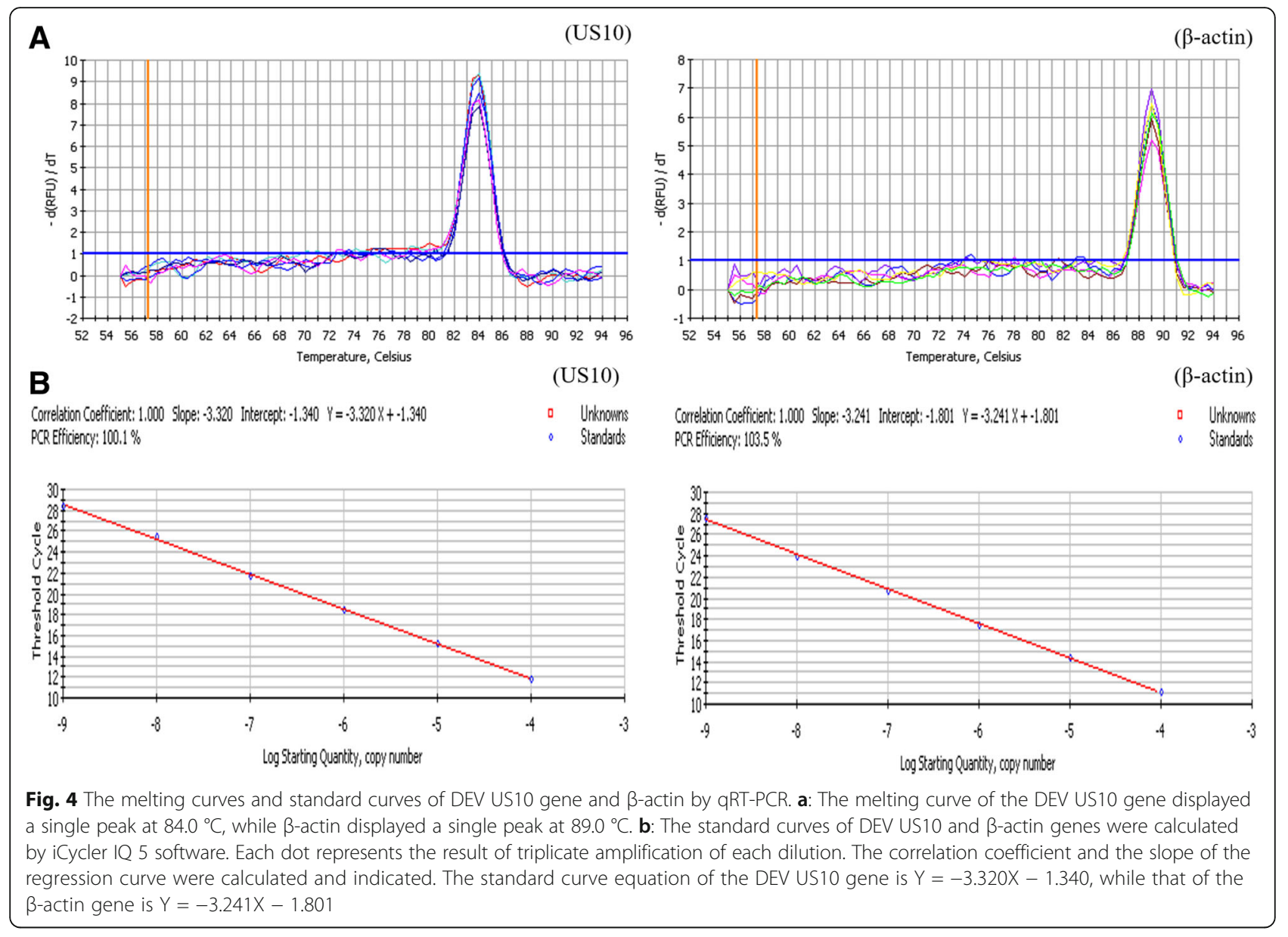

(Fig. 2a). The cell lysates of bacteria transformed with pET-32a $(+)$ or pET-32a(+)/US10 were blotted with antiUS10 serum, and a specific band corresponding to a fusion protein of $56 \mathrm{kDa}$ was obtained from pET-32a $(+) /$ US10. This result indicated that the antibody is specific for DEV US10 and not cross-reactive with pET-32a(+) $\mathrm{N}$-terminal vector-specific fusion elements (Fig. 2b). DEFs mock-infected or infected with DEV were also probed with anti-US10 serum to verify the ability to detect the desired protein. A target band of $36 \mathrm{kDa}$ was obtained from infected DEFs, which is consistent with the expected size of DEV US10 (Fig. 2c). Thus, the rabbit anti-US10 serum can specifically recognize this protein.

\section{Kinetics of DEV US10}

Western blot analysis was performed using protein samples collected at $4,8,24,48,60,72,84$, and $96 \mathrm{~h}$ postinfection (hpi). A specific protein band of approximately $36 \mathrm{kDa}$ was first detected at $8 \mathrm{hpi}$; expression gradually increased and peaked at $72 \mathrm{hpi}$, but began to decline at 84 hpi. US10 was still detected at 96 hpi (Fig. 3).

We then investigated the relative expression of the DEV US10 gene in infected DEFs at different time points using

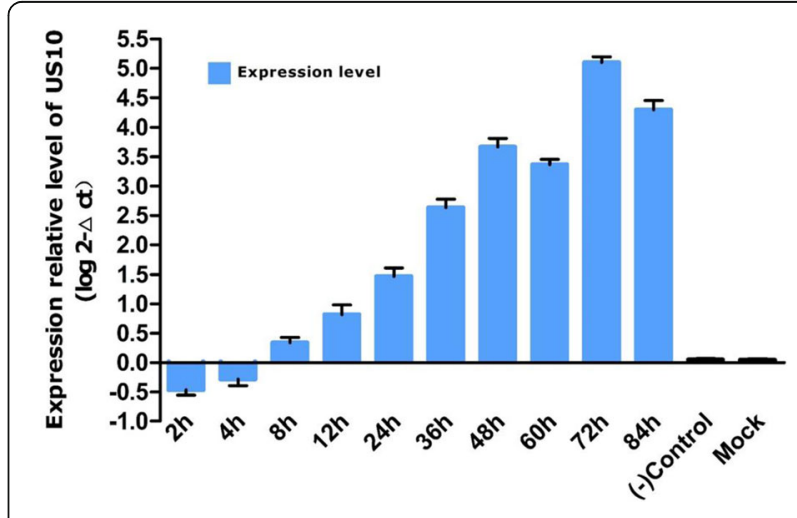

Fig. 5 Transcriptional analysis of the DEV US10 gene. Total RNA was isolated from the DEV-infected DEF cells at each post-infection time point and converted to CDNA. Samples of CDNA were amplified using qPCR and SYBR green detection. Data are presented as the fold change in the expression of the DEV US10 gene. The transcriptional expression of the DEV US10 gene was normalized to that of a reference gene ( $\beta$-actin) 


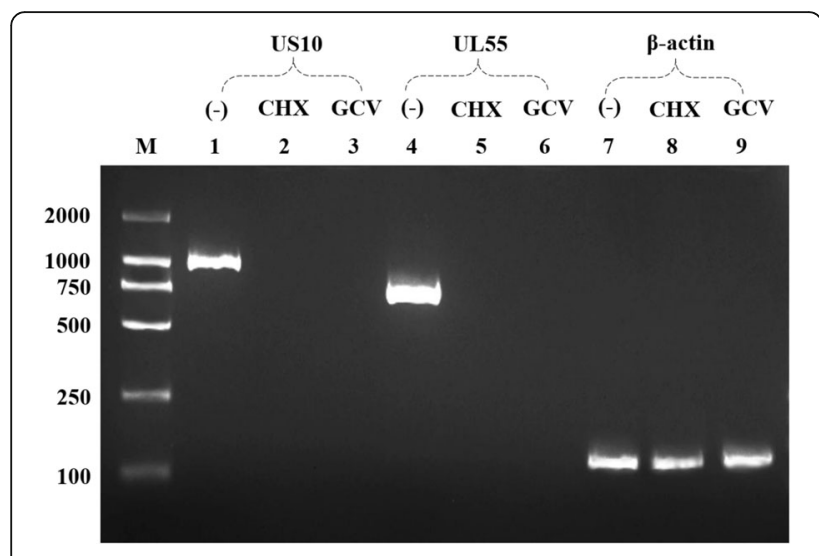

Fig. 6 Pharmacological inhibition test showed that US10 is a true late gene. Lane M: markers; lanes 1, 4, and 7: DEV-infected cells, without any drugs; lanes 2, 5, and 8: DEV-infected cells treated with $100 \mu \mathrm{g} / \mathrm{mL}$ cyclohexamide (protein synthesis inhibitor); lanes 3, 6, and 9: DEV-infected cells treated with $300 \mu \mathrm{g} / \mathrm{mL}$ ganciclovir (DNA polymerase synthesis inhibitor). DEV UL55 and $\beta$-actin genes were used as a $\gamma 2$ gene and a housekeeping gene, respectively
qRT-PCR. The specificity of the primer sets was verified using a melting curve (Fig. 4a). Standard curves, plotting plasmid copy number against the $\mathrm{Ct}$ values for US10 $(\mathrm{Y}=-3.320 \mathrm{X}-1.340)$ and $\beta$-actin $(\mathrm{Y}=-3.241 \mathrm{X}-1.801)$, were established to evaluate the efficiency of the assays. The approximately identical amplification efficiencies of US10 (100.1\%) and $\beta$-actin (103.5\%) yielded a correlation coefficient of 1.00 (Fig. 4b). Subsequently, total RNA was isolated and reverse-transcribed to cDNA, followed by $\mathrm{qPCR}$ and data processing to analyze the US10 transcription level (Fig. 5). The assays showed that transcription began at $8 \mathrm{~h}$ and gradually increased, reaching a peak at $72 \mathrm{~h}$. The expression and transcription levels of DEV US10 correlate with those of a $\gamma$ (late) gene.

To further verify the US10 gene type, the DNA polymerase inhibitor GCV and the protein synthesis inhibitor $\mathrm{CHX}$ were used to determine kinetic class. As shown in Fig. 6, $\beta$-actin (amplified length of $177 \mathrm{bp}$ ) was detected regardless of the presence or absence of drugs, while US10 (amplified length of $988 \mathrm{bp)}$ ) and UL55 (amplified length of $740 \mathrm{bp}, \mathrm{DEV} \gamma 2$ gene) were only detected when no drugs were present. Thus, US10 is a $\gamma 2$ (true late) gene

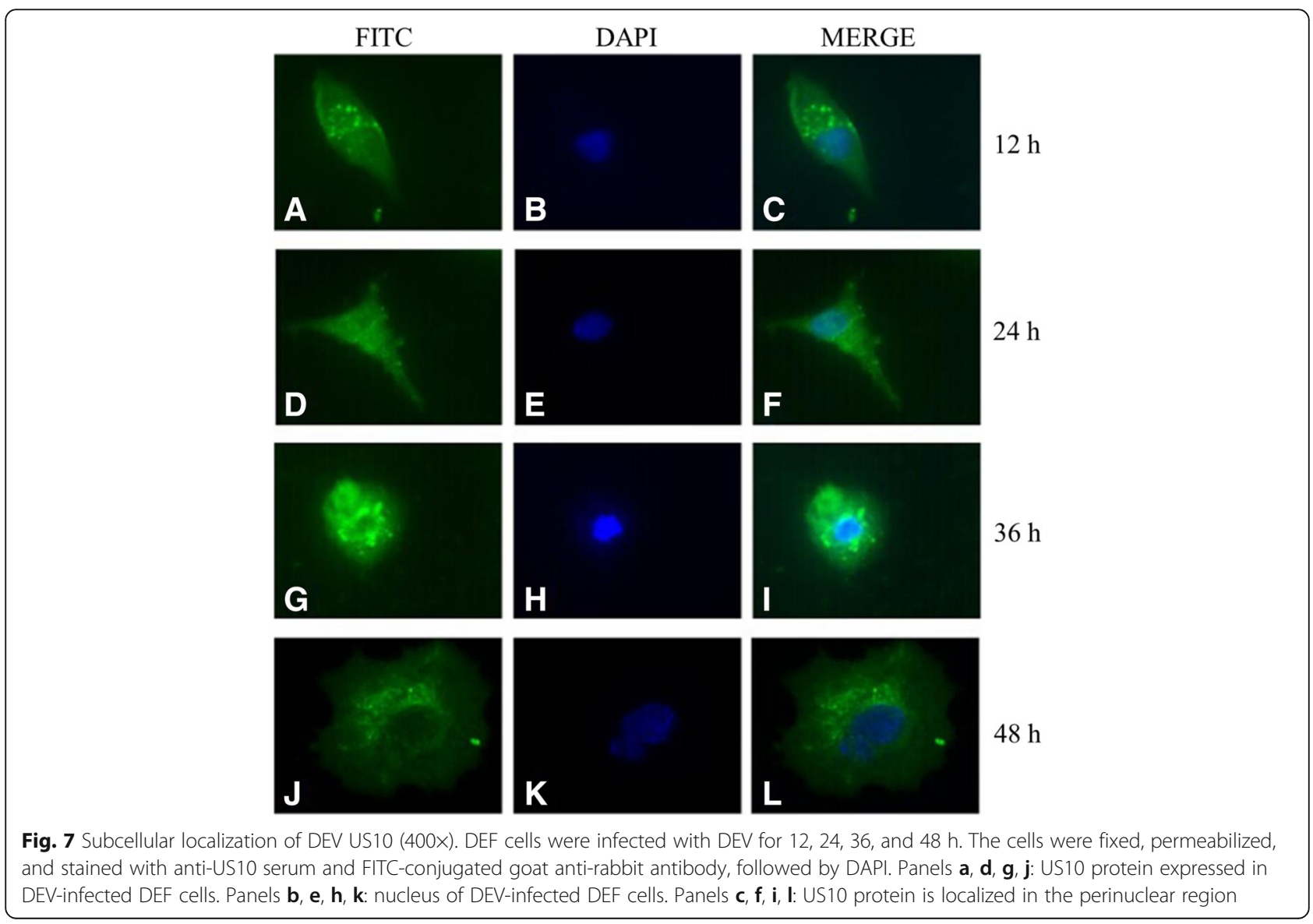




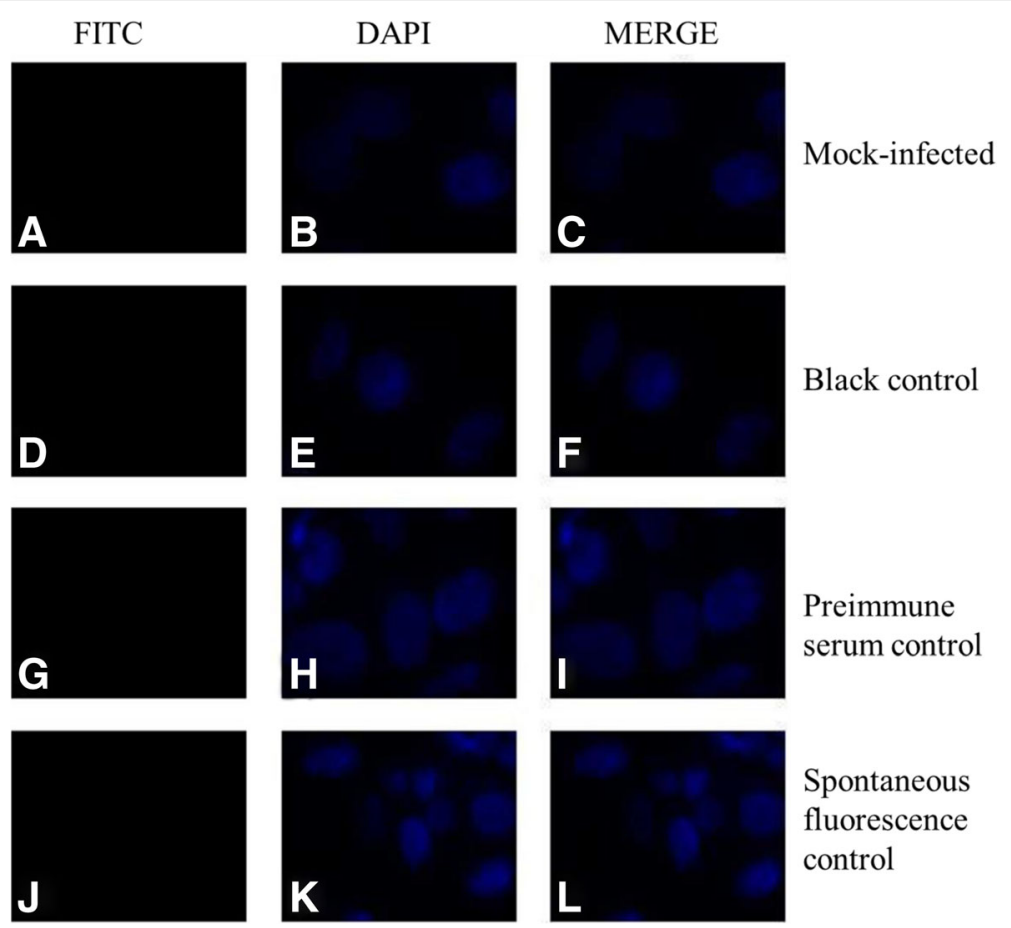

Fig. 8 Mock-infected cells, blank control, preimmune serum control, and spontaneous fluorescence control subjected to immunofluorescence analysis (400X). Panels $\mathbf{a}, \mathbf{d}, \mathbf{g}$, j: US10 protein was not detected in aboved control cells. Panels $\mathbf{b}, \mathbf{e}, \mathbf{h}, \mathbf{k}$ : nucleus of aboved control cells. Panels $\mathbf{c}, \mathbf{f}, \mathbf{i}, \mathbf{l}:$ There is no green fluorescence produced by false positives

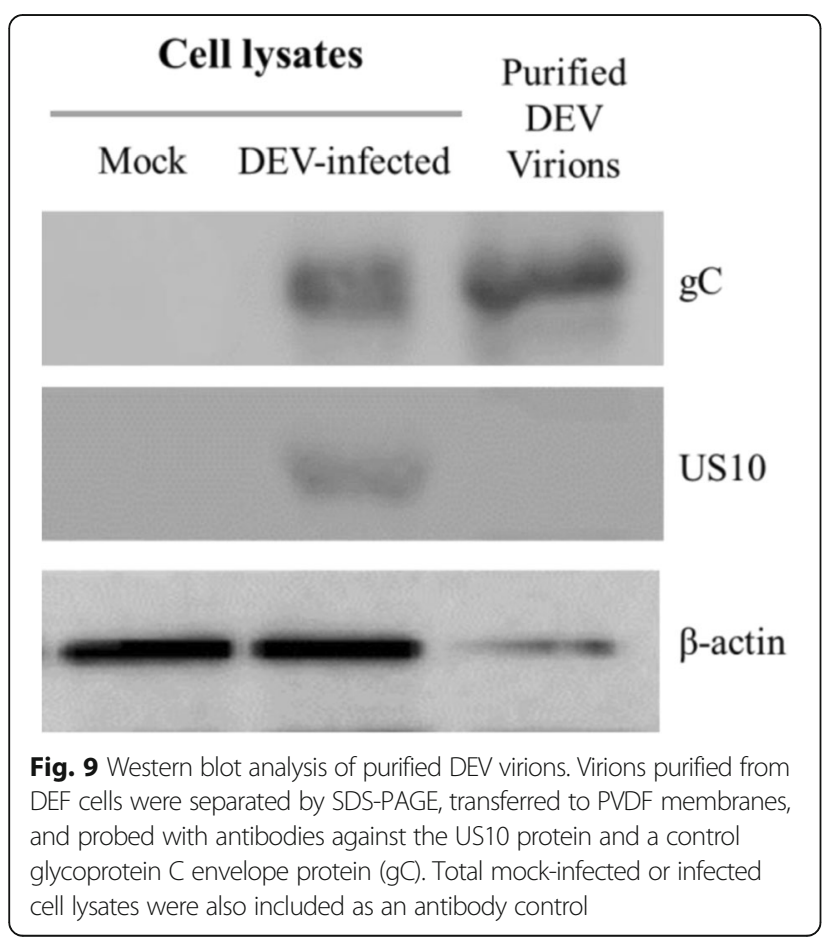

due to its strict dependence on the early synthesis of viral DNA and protein.

\section{Subcellular localization of DEV US10}

The intracellular distribution of DEV US10 was confirmed through IFA using rabbit anti-US10 serum. US10 protein-specific fluorescence was primarily localized to the cytoplasm at $12 \mathrm{hpi}$, but then gradually relocated to a perinuclear region. At $48 \mathrm{hpi}$, almost all US10-specific fluorescence localized around the nucleus; subsequently, this signal became sparser and weaker following cytoplasmic disintegration (Fig. 7). In contrast, no fluorescence was observed in control groups (Fig. 8). Thus, US10 is primarily localized within the cytoplasm.

\section{US10 Protein is a component of the virion}

The anti-US10 serum was used to probe the lysates of mock-infected cells, DEV-infected cells, and purified DEV virions (anti-gC serum was used as a positive control). The US10 protein could only be detected in DEV-infected cells, while $\mathrm{gC}$ protein could be detected in both purified virions and DEV-infected cells (Fig. 9).

The purified virions were also analyzed by mass spectrometry to identify the protein content. We identified 40 structural proteins in the purified DEV virions (data not shown), including DEV US10 protein (Table 2). One unique peptide of DEV US10 was detected, while three 
Table 2 Viral content of DEV extracellular virions (partial)

\begin{tabular}{llllllll}
\hline Protein & Description & Score & Mass & Matches & Sequences & emPAl & NCBI Accession \\
\hline UL44 & glycoprotein C & 97 & 47,836 & $6(3)$ & $6(3)$ & 0.22 & AJG04885 \\
US10 & Virion protein & 23 & 34,402 & $4(1)$ & $4(1)$ & 0.10 & AGW24857
\end{tabular}

unique peptides matched DEV gC $(P<0.05)$. The relative abundance of US10 was low based on the exponentially modified protein abundance index (emPAI). From the results of the above two methods, DEV US10 is a minor component of the virion and the failure of western blotting may be caused by its low abundance.

\section{Discussion}

Herpesvirus genes are expressed sequentially in three distinctly defined stages: $\alpha$ (immediate-early), $\beta$ (early), and $\gamma$ (late) genes $[1,15]$. The majority of the $\gamma$ gene products are virion structural proteins that contribute primarily to virion assembly and morphogenesis. Our research demonstrated that the DEV US10 gene can be classified as a $\gamma 2$ gene, as determined by western blotting, RT-PCR, and pharmacological inhibition experiments. The results are consistent with a report on the herpes simplex virus 1 (HSV-1) US10 gene [10], which was shown to encode a tegument protein. The function of HSV-1 US10 has not yet been characterized.

We also observed the subcellular localization of DEV US10 proteins by indirect immunofluorescence. They were abundantly distributed in the cytoplasm, specifically localizing around the nucleus, which was in accordance with earlier observations of Marek's disease virus (MDV) US10 proteins [23]. MDV US10 has been reported to specifically bind to chicken stem cell antigen 2 (SCA2, a putative Marek's disease resistance gene), but the mechanism and significance of their interaction are not well defined [12].

Recently, mass spectrometry has been widely used to analyze the structural proteome of herpesviruses, such as KSHV, HCMV, EBV, PRV, HSV-1, BoHV-4, and BoHV-1 [20-22, 24-28]. It has been proved that this approach is sufficiently sensitive to detect low-abundance proteins such as HSV-1 UL6 (a protein present in only 12 copies in mature virions), or the smallest proteins predicted to present in virions, such as HSV-1 US9 and UL11 (90 and 96 aa, respectively) [20]. To determine whether the DEV US10 protein is a structural component, mass spectrometry and western blotting were used to detect it in purified virions. Surprisingly, US10 was successfully detected by mass spectrometry, but not by western blotting. Similar conflicting result has also been reported on HSV-1 ICPO [29]. This discrepancy may be a result of US10 being a low-copy virion protein, which is difficult to detect with antibody. Hence, we assume that DEV US10 protein is a minor component of extracellular virions.

Overall, our data suggest that US10 is a $\gamma^{2}$ gene that probably functions as a virion protein, similar to HSV-1 US10 [10]. These data provide a foundation for future studies on duck enteritis virus US10.

\section{Conclusions}

Through experiments involving qRT-PCR, western blotting, and pharmacological inhibition tests, the DEV US10 gene was identified as a true late $(\gamma 2)$ gene. In infected cells, DEV US10 protein was initially diffusely distributed throughout the cytoplasm and gradually relocated to a perinuclear region. DEV US10 is detected in mature virions, so it is a virion protein. However, further studies are still needed to explore its functions.

\section{Abbreviations \\ BoHV-1: Bovine herpesvirus type 1; BoHV-4: Bovine herpesvirus type 4; CHX: Cycloheximide; DAPI: 4',6-diamidino-2-phenylindole; DEF: Duck embryo fibroblast; DEV: Duck enteritis virus; EBV: Epstein-Barr virus; EHV: Equine herpesvirus; GCV: Ganciclovir; HCMV: Human cytomegalovirus; HSV: Herpes simplex virus; IFA: Indirect immunofluorescence; IPTG: Isopropyl thiogalactoside; KSHV: Kaposi's sarcoma-associated herpesvirus; LC-MS/MS: Liquid chromatography- tandem mass spectrometry; MDV: Marek's disease virus; PRV: Pseudorabies virus; PVDF: Polyvinylidene fluoride; RT-PCR: Real-time quantitative reverse-transcription PCR; SDS-PAGE: Sodium dodecyl sulfate polyacrylamide gel electrophoresis}

\section{Acknowledgments}

We thank Liwen Bianji, Edanz Group China (www.liwenbianji.cn/ac), for editing the English text of a draft of this manuscript.

\section{Funding}

The research was supported by grants from the National Science and Technology Support Program (No. 2015BAD12B05), China Agricultural Research System (CARS-42-17), Special Fund for Key Laboratory of Animal Disease and Human Health of Sichuan Province (2016JPT0004), and Major Project of Education Department in Sichuan (16ZA0027).

\section{Availability of data and materials}

The datasets analyzed during the current study are available from the corresponding author on reasonable request.

\section{Authors' contributions}

DZ and ML carried out most of the experiments and drafted the manuscript. $A C$ and $M W$ critically revised the manuscript and the experimental design. YW, QY, ML, DZ, RJ, SC, KS, XZ, and XC helped in the experiments. All authors read and approved the final manuscript.

\section{Ethics approval and consent to participate}

This study was approved by the Animal Ethics Committee of Sichuan Agricultural University (2016-17).

\section{Consent for publication}

Not applicable.

Competing interests

The authors declare that they have no competing interests. 


\section{Publisher's Note}

Springer Nature remains neutral with regard to jurisdictional claims in published maps and institutional affiliations.

\section{Author details}

IInstitute of Preventive Veterinary Medicine, Sichuan Agricultural University, Wenjiang 611130, People's Republic of China. ${ }^{2}$ Avian Disease Research Center, College of Veterinary Medicine of Sichuan Agricultural University, Wenjiang 611130, People's Republic of China. ${ }^{3}$ Key Laboratory of Animal Disease and Human Health of Sichuan Province, Sichuan Agricultural University, Wenjiang 611130, People's Republic of China.

Received: 6 April 2017 Accepted: 31 August 2017

Published online: 20 September 2017

\section{References}

1. Samia AM. Viral infections of waterfowl: duck virus enteritis (duck plague). In: Swayne DE, Glisson JR, Mcdougald LR, Nolan LK, Suarez DL, Nair VL, editors. Diseases of poultry. 13th ed. Oxford: Wiley-Blackwell; 2013. p. 431-40.

2. Wang G, Qu Y, Wang F, Hu D, Liu L, Li N, et al. The comprehensive diagnosis and prevention of duck plaguein northwest Shandong province of China. Poult Sci. 2013;92:2892-8. DOl:10.3382/ps.2013-03356.

3. Baudet A. Mortality in ducks in the Netherlands caused by a filtrable virus: fowl plague. Tijdschr Diergeneeskd. 1923;50:455-9.

4. International Committee on Taxonomy of Viruses (ICTV) : The Online (10th) Report of the ICTV.https://talk.ictvonline.org/ictv-reports/ictv_online_report (2015). Accessed July 2015.

5. Wu Y, Cheng A, Wang M, Yang Q, Zhu D, Jia R, et al. Complete genomic sequence of Chinese virulent duck enteritis virus. J Virol. 2012;86(10):5965. DOI:10.1128/JVI.00529-12.

6. Wang J, Höper D, Beer M, Osterrieder N. Complete genome sequence of virulent duck enteritis virus (DEV) strain 2085 and comparison with genome sequences of virulent and attenuated DEV strains. Virus Res. 2011;160(1-2): 316-25. DOl:10.1016/j.virusres.2011.07.004

7. Yang C, Li Q, Li J, Zhang G, Li H, Xia Y, Yang H, Yu K. Comparative genomic sequence analysis between a standard challenge strain and a vaccine strain of duck enteritis virus in China. Virus Genes. 2014;48(2): 296-303. DOI:10.1007/s11262-013-1009-9.

8. Hu Y, Zhou H, Yu Z, Chen H, Jin M. Characterization of the genes encoding complete US10, SORF3, and US2 proteins from duck enteritis virus. Virus Genes. 2009;38(2):295-301. DOI:10.1007/s11262-009-0329-2.

9. Zhao Y, Wang JW, Liu F, Ma B. Molecular analysis of US10, S3, and US2 in duck enteritis virus. Virus Genes. 2009;38(2):243-8. doi:10.1007/s11262-008-0315-0.

10. Yamada H, Daikoku T, Yamashita Y, Jiang Y, Tsurumi T, Nishiyama Y. The product of the US10 gene of herpes simplex virus type 1 is a capsid/ tegument-associated phosphoprotein which copurifies with the nuclear matrix. J Gen Virol. 1997;78(11):2923-31.

11. Holden V, Yalamanchili R, Harty R, O'Callaghan D. Identification and characterization of an equine herpesvirus 1 late gene encoding a potential zinc finger. Virology. 1992;188(2):704-13.

12. Liu H, Niikura M, Fulton J, Cheng H. Identification of chicken lymphocyte antigen 6 complex, locus E (LY6E, alias SCA2) as a putative Marek's disease resistance gene via a virus-host protein interaction screen. Cytogenetic Genome Res. 2003;102:304-8. DOl:10.1159/000075767.

13. Sommer MH, Zagha E, Serrano OK, Ku CC, Zerboni L, Baiker A, et al. Mutational analysis of the repeated open reading frames, ORFs 63 and 70 and ORFs 64 and 69, of Varicella-zoster virus. J Virol. 2011;75(17):8224-39. DOl:10.1128/JVI.75.17.8224-8239.2001.

14. Wu Y, Cheng A, Wang M, Zhang S, Zhu D, Jia R, et al. Establishment of realtime quantitative reverse transcription polymerase chain reaction assay for transcriptional analysis of duck enteritis virus UL55 gene. Virol J. 2011;8(1):1-13.

15. Pellett PE, Roizman B. Chapter 59: Herpesviridae. In: Knipe DM, Howley PM. Cohen JI, Griffin DE, Lamb RA, Martin MA, Racaniello VR, Roizman B, eiditors. Fields Virology, 6th ed. Philadelphia: Lippincott Williams \& Wilkins; 2013, p. 1802-1822.

16. Wu Y, Cheng A, Wang M, Zhang S, Zhu D, Jia R, et al. Characterization of the duck enteritis virus UL55 protein. Virol J. 2011;8(1):1-15. DOl:10.1186/ 1743-422X-8-256.

17. Chang H, Cheng A, Wang M, Zhu D, Jia R, Liu F, et al. Cloning, expression and characterization of gE protein of duck plague virus. Virol J. 2010;7(1):1-11. DOI:10.1186/1743-422X-7-120.
18. Liu C, Cheng A, Wang M, Chen S, Jia R, Zhu D, et al. Duck enteritis virus UL54 is an IE protein primarily located in the nucleus. Virol J. 2015;12(1): 198-206. DOI:10.1186/s12985-015-0424-z.

19. Li L, Cheng A, Wang M, Xiang J, Yang X, Zhang S, et al. Expression and characterization of duck enteritis virus gl gene. Virol J. 2011;8(1):241. DOI:10.1186/1743-422X-8-241.

20. Loret S, Guay G, Lippé R. Comprehensive characterization of extracellular herpes simplex virus type 1 Virions. J Virol. 2008;82(17): 8605-18. DOI:10.1128/JVI.00904-08

21. Leroy B, Gillet L, Vanderplasschen A, Wattiez R. Structural proteomics of Herpesviruses. Viruses. 2016;8(2):50. DOl:10.3390/v8020050.

22. Johannsen E, Luftig M, Chase M, Weicksel S, Cahir-McFarland E, lllanes D, et al. Proteins of purified Epstein-Barr virus. Proc Natl Acad Sci U S A. 2004; 101(46):16286. DOl:10.1073/pnas.0407320101.

23. Mao W, Kim T, Cheng HH. Visualization of Marek's disease virus in vitro using enhanced green fluorescent protein fused with US10. Virus Genes. 2013:47(1):181. DOl:10.1007/s11262-013-0920-4

24. Zhu F, Chong J, Wu L, Yuan Y. Virion proteins of Kaposi's sarcoma-associated herpesvirus. J Virol. 2005;79(2):800-11. DOl:10.1128/JVI.79.2.800-811.2005.

25. Varnum S, Streblow D, Monroe M, Smith P, Auberny K, Pasa-Tolic L, et al. Identification of proteins in human cytomegalovirus (HCMV) particles: the HCMV proteome. J Virol. 2004;78(20):10960. DOl:10.1128/JV.78.20.10960-10966.2004.

26. Kramer T, Greco T, Enquist L, Cristea I. Proteomic characterization of Pseudorabies virus extracellular Virions. J Virol. 2011;85(13):6427-41. DOI:10.1128/JVI.02253-10

27. Lete C, Palmeira L, Leroy B, Mast J, Machiels B, Wattiez R, et al. Proteomic characterization of bovine herpesvirus 4 extracellular virions. J Virol. 2012;86: 11567-80. DOI:10.1128/JVI.00456-12.

28. Barber K, Daugherty H, Ander S, Jefferson V, Shack L, Pechan T, et al. Protein composition of the bovine Herpesvirus 1.1 Virion. Veterinary. Sciences. 2017; 4:11. DOl:10.3390/vetsci4010011.

29. Kalamvoki M, Qu J, Roizman B. Translocation and colocalization of ICP4 and ICPO in cells infected with herpes simplex virus 1 mutants lacking glycoprotein E, glycoprotein I, or the virion host shutoff product of the UL41 gene. J Virol. 2008:82(4):1701-13. DOl:10.1128/JVI.02157-07.

\section{Submit your next manuscript to BioMed Central and we will help you at every step:}

- We accept pre-submission inquiries

- Our selector tool helps you to find the most relevant journal

- We provide round the clock customer support

- Convenient online submission

- Thorough peer review

- Inclusion in PubMed and all major indexing services

- Maximum visibility for your research

Submit your manuscript at www.biomedcentral.com/submit
) Biomed Central 